\title{
Os resíduos e as sombras errantes: a alegria amarga de Natalia Ginzburg
}

The waste and the wandering shadows: Natalia Ginzburg's bitter joy 


\section{Resumo}

O trabalho busca pensar os estatutos que os ausentes e as lembranças ocupam nas narrativas ficcionais da escritora italiana Natalia Ginzburg. A proposta é traçar um percurso que passa pelo desfecho de quatro romances - La strada che va in città, Todos os nossos ontens, Caro Michele e La città e la casa - e, assim, lê-los com o amparo de alguns excertos de ensaios da própria autora, fragmentos de Espinosa relativos à falta e à capacidade de desejar e o conceito de experiência de Walter Benjamin. A hipótese de leitura consiste no delineamento da alegria possível, em um mundo esvaziado de sentido, a qual, diferente de uma felicidade idílica, passa pela ambivalência e pela sobrevivência da experiência por meio do trabalho de memória.

Palavras-chave: Natalia Ginzburg; literatura moderna; experiência; lembrança

\section{Abstract}

This piece tries to think the statutes that the absents and the remembrances have in the fiction's narrative by the Italian writer Natalia Ginzburg. The propose is to draw a path by four novel's endings - La strada che va in città, Tutti i nostri ieri, Caro Michele and La città e la casa - for read them with excerpts of Ginzburg's essays, fragments of Espinosa related with the absence and the capacity of desire and Walter Benjamin's concept of experience. The hypothesis of reading consists in the outline of a possible kind of joy in a world without sense, very different of an idyllic happiness because includes the ambivalence, and in the experience's survival through the work with the memory Keywords: Natalia Ginzburg; modern literature; experience; remembrace 
A lembrança foi perdendo

a trama exata tecida, até um sépia diluido de fotografia antiga.

Mas o que perdeu de exato de outra forma recupera: que boje qualquer coisa de uma traz de outra sua atmosfera João Cabral de Melo Neto

A cena de abertura de Amarcord" é entoada por uma mesma fala de vários personagens: "Le manine sono lassú e l'inverno non c'è più", fazendo referência a flores que anunciam a chegada da primavera. $\mathrm{Na}$ cena final, embora ninguém fale, as mesmas flores voam pelo cenário para anunciar que, com o fim do inverno, começa a primavera. Entre esses dois momentos, não há um enredo propriamente dito, a narrativa é guiada por memórias, encadeadas por um fio delicado, tecido, sobretudo, pela sucessão de estações do ano, entre lembranças de travessuras escolares, primeiros amores, experiências sexuais paradigmáticas, tolos e ternos litígios familiares, jogos, eventos de confraternização citadinos, excessos hiperbólicos de histórias transmitidas oralmente, perseguições políticas do regime fascista, mortes e partidas. É possível depreender tanto o irrefreável do curso do tempo quanto o poder das recordações em mapearem tempos e espaços. Fica a sugestão de que o ato de representar lembranças, encadeadas pelo ritmo de primaveras que sucedem invernos, também envolve uma postura ética: mais do que a constância da felicidade, a alegria estaria na capacidade de viver eventos tanto da ordem da penúria quanto do êxtase dos momentos que extraem sorrisos dos lábios.

O filme com matizes biográficos de Fellini será um amparo para a leitura do caminho que leva à cidade, título do primeiro romance de Natalia Ginzburg e eixo de análise para o contraste entre a primeira e a última narrativas ficcionais da autora: $L a$ strada che va in città (1942) e La città e la casa (1984). O percurso se dará através da leitura dos finais de duas outras narrativas do entremeio - Todos os nossos ontens (1952) e Caro Michele $^{3}(1973)$ - a fim de delinear os estatutos que os vazios deixados pelos mortos podem ter.

1 FELLINI, Federico. Amarcord, 1973.

2 GINZBURG, Natalia. Todos os nossos ontens, 2020.

3 Idem, Caro Michele, 2009. 
La strada che va in città é composto por um movimento de descobertas, nascimentos e ampliações de horizontes. Ainda que haja uma dose de desolamento, particularmente no desfecho, há certa dinâmica de extensão ascendente: do pouquíssimo que se sabe e se conhece ao estabelecimento no ambiente urbano, em que as coisas são maiores e com possibilidades aparentemente, mais amplas. La città e la casa é um romance epistolar, composto por uma série de correspondências que se assemelham a monólogos de pessoas que precisam de papel, caneta e destinatário para se sentirem menos solitárias. O tempo passa pelas datas nos cabeçalhos das missivas, pelas perdas sucessivas e pelo impossível de ter um lugar para si.

A hipótese seria que a supressão do caminho que separa o lugar conhecido da cidade e a sua substituição por uma conjunção aditiva implicam em mudanças no enunciado, a constituição dos personagens e como eles se relacionam com perdas, e na enunciação, o progressivo emudecimento que transparece nas configurações formais. Junto à prevalência do espaço nos títulos dos romances - La strada che va in città e La cittá e la casa - e marcando as distinções formais entre eles, busco propor a possibilidade de sobrevivência da experiência, nos termos de Benjamin, por meio da ambivalente alegria que pode brotar do trabalho da memória como eixo comum da escrita de Ginzburg.

\section{O caminho e a cidade}

Um aspecto que une os quatro textos, selecionados como corpus desta pesquisa, são as marcas deixadas por ausentes que fecham as narrativas. Começando pelo primeiro romance da escritora, La strada che va in città termina da seguinte forma:

\footnotetext{
Não dissemos nada sobre o Nini em nenhum momento ao longo do tempo que passamos juntos no café, como se tivéssemos esquecido que ele também gostava de se sentar no café para fumar e falar, atravessado na cadeira, com os dedos nos cachos e o queixo empinado. Mas parecia cada vez mais difícil pensar nele, em seu rosto e nas coisas que ele sempre dizia. Tudo parecia distante e dava medo pensar porque os mortos metem medo ${ }^{4}$.
}

4 Idem, Opere, volume primo, 1986, p. 76. Live tradução de "Non avevamo detto niente del Nini, in tutto il tempo che eravamo stati insieme al caffè come se avessimo dimenticato che anche a lui una volta piaceva sedersi al caffè, a fumare e a parlare, buttato di traverso sulla seggiola con le dita nel ciuffo e il mento alzato. Ma diventava sempre piú difficile pensare a lui, facci che aveva e alle cose che diceva sempre, e mi sembrava già così lontano che metteva paura perché i morti mettono paura”. 
Nini é uma espécie de primo de consideração da protagonista e narradora Delia, um grande amigo e o primeiro amor. Ele é o personagem que abre a narrativa, a partir da breve explicação sobre quais acontecimentos o levaram a morar com a narradora e a apresentação de eventos iterativos, escritos no imperfeito, que caracterizam a rotina da casa interiorana que não era lar - repulsiva e excessivamente povoada nas palavras de Delia. Do passado imperfeito ao presente do medo que os mortos despertam, o romance termina no ponto em que a narradora está na cidade na sua própria casa, não mais na determinada pelos pais. O desfecho segue a linha do que Cesare Garboli ${ }^{5}$ comenta sobre as histórias de Ginzburg: a destruição de uma primeira toca, primitiva e paradigmática, para a construção de uma próxima. No entanto, a segunda toca nesse romance - resultado do casamento da protagonista com o personagem que, segundo os parâmetros do povoado de origem da narradora, incorpora os ideais de riqueza e opulência - é delineada com alguma frivolidade. A personagem esperava encontrar um lar quando saísse da casa dos pais, mas não é o que acontece. No desfecho, o lugar onde mora, assim como a primeira casa, é um ambiente que não implica pertencimento porque não é reconfortante ou acolhedor, e ela se sente alheia ao local.

Nini representava algo completamente oposto: tão criativo quanto autodestrutivo, ele ia na contramão dos padrões enlatados burgueses. Como em outros livros de Ginzburg, ele parece ser uma metonímia de determinada dimensão de liberdade absolutamente incongruente com os protocolos estabelecidos, como se sua morte precoce simbolizasse a inviabilidade de uma postura transgressora. Em Invito alla lettura di Natalia Ginzburg, Elena Clementelli define o personagem como uma promessa de amplitude análoga à cidade, só que, no caso dele, a morte prematura o relega a ser uma potência tolhida, enquanto que a experiência da narradora na cidade se restringe à esterilidade de uma vida frívola.

\footnotetext{
A sua existência desordenada, os seus livros, a sua postura inconformada, a sua absoluta liberdade nos modos de pensar e agir o fazem completamente diferente de todos os outros. Nini é também um símbolo, como é a cidade. Mas, enquanto a cidade se mostra indiferente, e em um certo ponto irrealizável e abstrata, Nini é uma referência concreta e viva. Ele é uma promessa que poderia ser cumprida se a morte não intervisse e minasse essa possibilidade ${ }^{6}$.
}

5 GARBOLI, Cesare. Opere di Natalia Ginæ̧burg, 2015.

6 "Con la sua esistenza disordinata, i suoi libri, il suo anticonformismo, la sua assoluta libertà nel pensare e nell'agire che lo rendono cosí diverso da tutti gli altri. Anche il Nini è un simbolo, cosí come lo è la città, ma, mentre la città resta indifferente e in un certo senso irragiungibile e astratta, il Nini è un richiamo concreto, vivo, è una promessa che potrebbe attuarsi se non intervenisse la morte e strapparlo a questa possibilità" (CLEMENTELLI, Elena. Invito alla lettura di Natalia Ginz̧burg, 1986, p. 57). 
O medo que os mortos despertam poderia ser entendido tanto como a impossibilidade de esquecer a singularidade de Nini e as marcas deixadas por ele, quanto uma resistência em recordá-las, já que o inconformismo do personagem seria também uma reafirmação da futilidade do desfecho da protagonista. A lembrança é interrompida nesse ponto porque o sentido da vida de quem pode lembrá-lo seria delineado de tal modo que o fascínio da liberdade deveria ser podado e domesticado.

Em um ensaio de dois anos depois, "Inverno em Abruzzo", o período em que Ginzburg viveu como exilada política é relatado segundo as distensões temporais que o afastamento geográfico provoca. Os espaços conhecidos são interditados, o que é expresso pela distância física que se impõe entre os pronomes possessivos e tudo que era conhecido: "Aquilo era um exílio: nossa cidade estava longe, e longe estavam nossos livros, os amigos, as várias e cambiantes vicissitudes de uma verdadeira existência" Já o tempo de quem é afastado à força da própria terra parece sofrer uma estranha distensão: como a autonomia foi negada, o fim do período de exceção precisa do condicional para ser expresso. "O fim do inverno despertava em nós uma inquietude. Talvez alguém viesse nos visitar: talvez finalmente aconteceria alguma coisa. Nosso exílio afinal devia ter um fim"». A falta de lugar, portanto, tem efeitos na possibilidade de emprego de pronomes da primeira pessoa como referência de pertencimento e de determinação do próprio futuro: o final do exílio só pode ser imaginado como um talvez. O texto é encerrado com a proposta de que a sorte humana "transcorre nessa alternância de esperanças e nostalgias" e, logo em seguida, certa noção de felicidade é ligada a um passado irremediavelmente perdido:

\footnotetext{
Meu marido morreu em Roma, nas prisões de Regina Coeli, poucos meses depois de termos deixado o vilarejo. Diante do horror de sua morte solitária, das angustiantes vacilações que a antecederam, eu me pergunto se isso aconteceu a nós, a nós, que comprávamos as laranjas de Girò e íamos passear na neve. $\mathrm{Na}$ época eu tinha fé um futuro fácil e feliz, rico de desejos satisfeitos, de experiências e de conquistas em comum. Mas aquele era o tempo melhor da minha vida, e só agora, que me escapou para sempre, só agora eu sei ${ }^{10}$.
}

O final desse texto de 1944 tem o tom de quem lastima a morte de uma noção idílica de felicidade, isto é, um paradigma de bem-estar no qual não há contraponto de desprazer, ele envolve "desejos satisfeitos" e "experiências em comum". O ponto

7 GINZBURG, Natalia. "Inverno in Abruzzo", 2015, p. 14.

8 Ibidem, p. 19.

9 Ibidem, p. 19.

10 Ibidem, p. 19. 
final do ensaio não encerra apenas o relato e a reflexão sobre as memórias do desterro e seus efeitos nas possibilidades de estar no mundo. Ele é também relativo a certa perspectiva que morre junto com o marido, irrecuperável porque instaura uma ferida não suscetível a apagamentos.

A alternância entre nostalgia e esperança delineia o ângulo de visão que pode suceder a morte do idílio, porque marca uma concepção da vida em que a incompletude é incontornável: seja qual for o eixo de oscilação, tem-se uma dose de ausência. A invariabilidade da falta, com Espinosa, pode ser lida segundo suas implicações éticas porque ela seria tanto um elemento propulsor do desejo, quanto configuraria certa imobilidade do tempo. Segundo o filósofo, a saudade pode ser aproximada e afastada da capacidade de desejar: assemelha-se à medida que expressa uma carência, "ou seja, o Apetite de possuir uma coisa" ", e se distancia porque tal apetite é "simultaneamente coibido pela memória das outras coisas que excluem a existência da coisa apetecida" ${ }^{\text {"12: }}$

\begin{abstract}
Quando recordamos uma coisa somos por isso dispostos a contemplála com o mesmo afeto que teríamos se a coisa estivesse presente; mas esta disposição ou esforço é no mais das vezes inibida, enquanto estamos acordados, por imagens de coisas que excluem a existência daquela que recordamos. Assim, quando nos lembramos de uma coisa que nos afeta com algum gênero de Alegria, por isso nos esforçamos para contemplá-la como presente com o mesmo afeto de Alegria, esforço que é imediatamente inibido pela memória das coisas que excluem a existência dela ${ }^{13}$.
\end{abstract}

O pêndulo entre nostalgia - como referência de passado - e esperança possibilidade de vislumbrar o porvir - poderia ser entendido como a reafirmação da falta de algo valoroso, tanto como o que é movido pelo desejo de suprimi-la quanto algo que imobiliza por causa da dor da perda. Parece de suma importância manter a ambivalência porque essa característica reaparece a todo tempo na obra de Ginzburg. Em "O meu ofício", por exemplo, a escrita - descrita como um processo capaz de dar lugar e retirar do exílio - é expressa como algo que "se nutre de coisas horríveis, devora o melhor e o pior de nossas vidas, tanto nossos sentimentos bons quanto os ruins correm em seu sangue" ${ }^{14}$.

Em La strada che va in città, o assombro que os mortos causam é escrito com o presente. Em “Inverno em Abruzzo", é sugerida a ambivalência que a falta pode ter ao passo que se relata a perda irreversível de certa expectativa de futuro. Já no ensaio sobre a

11 ESPINOSA, Ética, 2015, p. 357.

12 Ibidem, p. 357.

13 Ibidem, p. 358.

14 GINZBURG, Natalia. “O meu ofício”, 2015, p. 90. 
prática de escrita, cinco anos depois do texto da morte do idílio, a possibilidade de ter um lugar é delineada como ação corrente: pelo processo da escrita se pode estar fora do exílio, e a alegria por ter um ofício passa pela coexistência dos sentimentos bons e dos ruins. Em Todos os nossos ontens, é possível olhar, nem que num relance, para os mortos, e o imperfeito é deslocado para o futuro como uma expressão de tudo o que não se sabe:

E riram - um pouco, os três juntos - Anna, Emanuele e Giustino eram muito amigos e estavam contentes de serem eles três que estavam pensando nos que tinham morrido, na longa guerra, na dor, nos clamores e na longa vida que tinham pela frente, difícil e repleta de coisas que eles não sabiam fazer ${ }^{15}$.

Junto aos mortos e à destruição da guerra, resta a possibilidade de olhar adiante, ainda que haja um profundo desconhecimento relativo ao porvir. E há também a abertura para um contentamento no desenrolar: a possível alegria está no decorrer do processo, não em um passado remoto que precede as perdas, nem num futuro ideal. Os três sobreviventes passaram por profundas subtrações - de pais, irmãos, marido -, mas as mortes, aqui, não inviabilizam que o olhar se vire à frente.

A epígrafe de Todos os nossos ontens é um fragmento de Macbeth do qual é extraído também o título do romance: "A nós, tolos, todos esses ontens iluminaram/ O caminho ao pó da morte" ${ }^{16}$. O peso do passado, que ilumina o caminho para a morte, é lido por Giacomo Magrini, no prefácio que escreve para esse romance, como a representação de uma "nua realidade"17 e de um tempo que passa mais pelo envelhecimento do que pelo amadurecimento. Ele ainda sugere que a narrativa dá mais peso ao caminho do que ao processo de esclarecimento - como na trama de Shakespeare, na qual o trecho aparece num ponto em que Lady Macbeth toma consciência do peso da culpa e do sangue que carrega.

A consciência também pode aparecer, mas é ela sempre subordinada ao caminho, tem um papel secundário, isto é, o que é premente para a

15 Idem, Todas as nossos ontens, 2020, p. 321.

16 SHAKESPEARE, William. A tragédia de Macbeth, 2016, p. 210.

17 "La coscienza può anche venire, ma sempre subordinata e secondaria rispetto al cammino. Ciò che premme alla narratrice è di guidare i suoi personaggi attraverso tutto il bosco alla fine del bosco, lasciando insuperato e intatto il trauma che ha modificato o inciso i loro lineamenti. La guerra e la resistenza non le interessano tanto come oggeto di raprresentazione, quanto come contegno della guida e modalità del cammino"(MAGRINI, Giacomo. "Introduzione", 1996, p. 10). 
narradora é guiar os seus personagens pelo decorrer do bosque, até o seu fim. O trauma, que modificou ou rompeu os contornos dos personagens, é deixado intocado ou como não superado. A guerra e a resistência não interessam tanto como objetos de representação quanto o teor do encaminhamento e da modalidade do caminho ${ }^{18}$.

A prevalência do caminho teria uma dimensão ética, porque trata da postura perante os traumas e as incisões que a aspereza da vida provoca nas existências retratadas. As dores da perda estão dadas, e a representação do caminho passa pela forma que os personagens podem reagir a elas. Em determinado ponto de Todos os nossos ontens, um personagem apresenta a seguinte definição de liberdade: "era livre quem aceitava viver o que tinha para ser vivido. Era livre quem fazia dos pensamentos saúde e riqueza, e não uma armadilha para se enforcar" 19 . Esse mesmo personagem dirá que a "alegria é também feita de arrepios gelados, um medo enorme de errar e vontade de correr para frente" ${ }^{20}$. À luz desses fragmentos e do comentário de Magrini, estimaria que a alegria na prosa de Natalia é, sobretudo, uma afirmação da vida, principalmente na adversidade. Mesmo que vinculada a um tempo ido, a alegria só poderia ter lugar se partisse de uma postura perante o processo em curso. Não se trata de um passado de possibilidades perdidas nem de um futuro promissor, o olhar que pode garantir algum brilho às recordações precisa de comprometimento com o presente. Não existe "correr para frente" com pés imobilizados por dores ou expectativas. Aceitar o que tem para ser vivido pressupõe uma ancoragem no hoje, por mais ingrato que ele seja.

\section{A alegria e a lembrança}

No ensaio "Un matrimonio in provincia", o termo alegria aparece encadeado com os adjetivos 'estranho', 'áspero' e 'cinzento’”21. E é com eles que busco pensar a alegria possível que sucede a morte do idílio e ler os desfechos de Caro Michele e La città e la casa. O primeiro é um romance semi epistolar que acompanha a errância do personagem que dá título ao livro e à espera por parte dos que ficam. A carta de desfecho é escrita por um amigo de Michele e endereçada à irmã do jovem, que fora morto em uma passeata política. Osvaldo, o autor da missiva, visita a última casa onde Michele morou e narra a sensação ambivalente de encontrar um resto do ausente.

18 Ibidem, p. 10.

19 GINZBURG, Natalia. Todas os nossos ontens. 2020, p. 143.

20 Ibidem, p. 145.

21 Idem, "Un matrimonio in provincia", 2003, p. 35 
Os rapazes de hoje não têm memória e, sobretudo, não a cultivam, e você sabe que Michele também não tinha memória, ou melhor, não se convencia jamais a absorvê-la e a cultivá-la. Entre os que cultivam as lembranças talvez ainda estejamos você, sua mãe e eu, você por temperamento, eu e sua mãe por temperamento e porque na nossa vida atual não há nada que valha os lugares e os instantes encontrados durante o percurso. Enquanto eu vivia ou via esses instantes ou esses lugares, eles tinham um esplendor extraordinário mas por eu saber que me dedicaria a recordá-los. Sempre me magoou profundamente que Michele não quisesse ou não pudesse conhecer esse esplendor, e seguisse adiante sem jamais virar a cabeça para trás. Porém, creio que, sem saber, ele contemplasse esse esplendor dentro de mim. E muitas vezes pensei que, ao morrer, talvez ele tenha conhecido e percorrido num relance todos os caminhos da memória, e esse pensamento é para mim um consolo, porque nos consolamos com nada quando não temos mais nada, e até mesmo ter visto naquela cozinha aquela blusa esfarrapada que não recolhi foi para mim um estranho, gélido, desolado consolo ${ }^{22}$.

A lembrança, de acordo com o autor da carta, é traço de temperamento ou algo que vem ocupar uma lacuna: a falta do que possa fazer valer "os lugares ou instantes encontrados no caminho". A recordação vem ocupar um vazio estabelecido no presente e é nesse sentido que a lembrança aparece como o que poderia dar "um esplendor extraordinário" ao que se vive. Ainda que Osvaldo enuncie a ausência do que poderia ter valor em sua vida, ele encontra consolo em uma simples blusa puída.

Em Journal de Denil, Barthes parece expressar uma alegria áspera e amarga análoga à do personagem de Ginzburg: diante do vazio deixado pela mãe que falecera, no apartamento em que ela morava é possível sentir alguma coisa que não a pungência dilacerante da perda: "É lá onde as coisas vão menos mal, é quando estou numa situação onde há um tipo de prolongamento da minha vida com ela (apartamento)"²3. Para quem passa por uma subtração dolorosa, o cultivo de resíduos do morto seria uma forma de não estar apenas passivamente como objeto da perda: o recurso que sobra para o vivo pode ser o esforço de tornar as coisas ligeiramente menos dolorosas.

Em contraste com a noção de valor palpável, há algo de inestimável no encontro com um resíduo de um ente querido e ausente. De certa forma, é como se o nada que consola fosse diferente do nada que configura as circunstâncias da vida do remetente. De volta a Espinosa, a alegria da falta, aqui, parece estar no meio do caminho das propostas do filósofo, porque a blusa esfarrapada, embora reafirme o vazio deixado

22 Idem, Caro Michele. 2009, p. 154.

23 "Et là où ça va moins mal, c'est quand je suis dans une situation où il y a une sorte de prolongement de ma vie avec elle (appartement)” (BARTHES, Roland. Journal de deuil, 2009, p. 206). 
por Michele, também consola e dá singularidade ao papel que o remetente pode atribuir a si na vida do ausente: ele estima que possibilitou a um jovem, parte de uma geração que não cultiva a lembrança, percorrer os caminhos da memória.

A adjetivação em cadeia - "estranho, gélido, desolado consolo" -, como na definição de alegria no ensaio em "Un matrimonio in provincia", não é unívoca. Talvez seja possível supor que isso também é um resíduo de uma morte menos tangível, aquela relacionada ao que cai por terra quando uma noção idílica de felicidade torna-se impossível. Com as palavras de Ginzburg, proporia que a felicidade configura uma antítese da alegria amarga, cinzenta e áspera, essa última mais próxima da alternância entre nostalgia e esperança.

Em Caro Michele, aliás, a felicidade aparece por mais de uma vez escrita no subjuntivo: "Desejo-lhe todo o bem possível, e espero que você seja feliz, admitindo que a felicidade exista. Eu não acredito que exista, mas os outros acreditam, e ninguém disse que os outros não têm razão" "24. Se, em "Inverno em Abruzzo", a felicidade é apresentada como uma fantasia da juventude que se mostra insustentável depois de um evento terrível, nesse romance, ela é mencionada com alguma ironia e um caráter genérico: a felicidade é uma crença dos "outros", um sujeito indeterminado, se não em termos gramaticais, em discursivos ele ganha a acepção sem face. Enquanto que o que está sendo lido como alegria - o desolado e gélido consolo - só pode ter lugar se projetado por um olhar específico: é possível encontrá-la numa blusa esfarrapada enquanto a felicidade só existe como uma possibilidade colocada em xeque assim que enunciada como voto futuro - "Mando-lhe um abraço e votos de felicidade, admitindo que a felicidade exista, coisa que não deve ser de todo excluída, ainda que raramente vejamos traços dela no mundo que nos foi oferecido" ${ }^{25}$. A voz passiva chama a atenção: a felicidade não se mostra no mundo oferecido, enquanto que Osvaldo - e Barthes enlutado pela mãe - se desloca para procurar por um resíduo do ausente. Por isso que fica a proposta de uma dimensão ética: a alegria das flores que anunciam o fim do inverno, do que vai menos mal no apartamento da mãe morta e do encontro com a blusa esfarrapada só existe porque alguém se propõe a enxergar. São, portanto, imagens incongruentes com a voz passiva.

No posfácio que escreve para a edição brasileira de Caro Michele, Vilma Arêas lê na narrativa um convite para que "enterremos nossos mortos e, num relance, compreendemos que existe também no livro um desejo talvez de alegria e uma compreensão realista de felicidade"26, que envolve também "o entulho do que se

24 GINZBURG, Natalia. Caro Michele. 2009, p.114.

25 Ibidem, p. 96.

26 ARÊEAS, Vilma. “Ofício de escrever”, 2009, p. 174. 
vive" ${ }^{27}$. A noção de resíduo, com o amparo das palavras da crítica, ganha ainda outra dimensão: não se trata apenas do que um ausente deixa para trás, é também algo da ordem do descarte, do que poderia passar despercebido ou ser entendido como lixo. Entulho, então, será a palavra que levará ao trapeiro sucateiro de Benjamin. Nesse caminho, a alegria poderia ser aproximada do vigor de quem se propõe a encontrar vida nos restos da cidade, tudo que ela "jogou fora, tudo o que ela perdeu, tudo o que ela desprezou, tudo o que destruiu"28. O poeta seria, então, aquele capaz de compilar

os anais da devassidão, o cafarnaum da escória; separa as coisas, faz uma seleção inteligente; procede como um avarento com seu tesouro e se detém no entulho que, entre as maxilas da deusa da indústria, vai adotar a forma de objetos úteis e agradáveis ${ }^{29}$.

Em uma primeira dimensão, fica a tentativa de ressaltar o caráter ético da alegria, quando ela exige uma posição ativa para ser encontrada, já que poderia facilmente passar despercebida, no caso do olhar ficar engessado segundo as formas pré-moldadas da lógica de produção em cadeia industrial. Mas há também a dimensão do trabalho de memória, é o que Jeanne Gagnebin propõe na sua leitura de Benjamin: o sucateiro, como alguém movido "pelo desejo de não deixar nada se perder"30, seria aquele que recolhe os restos e, com eles, resgata o que poderia ser facilmente relegado ao completo apagamento já que se trata de algo "desprovido de durabilidade que podia ligá-lo à escrita, entregue à caducidade e mesmo à clandestinidade, o rastro se aproxima dos restos, dos detritos, da sucata, do lixo" ${ }^{31}$. A memória, portanto, é o que pode salvar a blusa esfarrapada do estatuto de descarte, é o que pode garantir valor ao que seria entendido pelos "outros", que acreditam na felicidade oferecida, como condenado. Trata-se então de um valor atrelado ao olhar que pode encontrar tesouros em meio ao entulho, e a investigação sobre o imponderável desse valor será traçada com o termo experiência.

Ainda em 1913, a experiência é colocada como algo próprio da infância e que seria perdido na vida adulta. Benjamin, portanto, ao começar a dar contornos para este que virá a ser um dos seus conceitos centrais, subverte o entendimento comum do termo. Diferente da suposição do conhecimento que se adquire com o passar dos anos,

27 Ibidem, p. 174.

28 BENJAMIN, Walter. Obras escolhidas III: Charles Baudelaire: um lírico no ange do capitalismo, 2000, p.77.

29 Ibidem, p. 78.

30 GAGNEBIN, Jeanne. Lembrar Escrever Esquecer, 2006, p. 54.

31 Ibidem, p. 177. 
a experiência proposta incialmente passaria por um sentido contrário: é o acúmulo dos anos que minaria a possibilidade de sua emergência. A experiência da ordem do acúmulo é lida como "inexpressiva, impenetrável, sempre a mesma"32. O portador da experiência dessa natureza, de antemão, "desvaloriza os anos que estamos vivendo, converte-os na época das doces asneiras que se cometem na juventude, ou no êxtase infantil que procede a longa sobriedade da vida séria" ${ }^{33}$. Nesse sentido, o erro seria o parâmetro estabelecido como o que deve ser evitado, e também Benjamin recorre a Espinosa para propor que o contracampo dessa noção de experiência - a do "eu já vivenciei tudo isso" - é uma concepção de erro "como um alento para a busca de verdade" ${ }^{34}$. De certo modo, a experiência que Benjamin escreve com aspas é a que opera segundo a lógica do capitalismo: a do acúmulo de certezas.

A experiência sem aspas seria a que entra em extinção ao longo do século XX, e é também com uma imagem do capitalismo que ele a reapresentará em "O narrador": "as ações da experiência estão em baixa, e tudo indica que continuarão caindo até que seu valor desapareça de todo" ${ }^{35}$. A metrificação da experiência segundo o léxico do mercado financeiro parece ser uma provocação para destacar seu caráter artesanal, seu valor intangível, radicalmente incongruente com a reprodutibilidade técnica. A raridade da experiência é colocada na sua incompatibilidade com a informação, cujo caráter pressupõe plausibilidade, porque ela opera com o improvável e, assim, seria capaz de comportar uma vida suscetível à germinação semelhante "a essas sementes de trigo que durante milhares de anos ficaram fechadas hermeticamente nas câmaras das pirâmides e que conservamos até hoje sua força germinativa"36. É algo também da ordem da perda de tempo - e não do ganho da produtividade do capitalismo - já que "o tédio é o pássaro de sonho que choca os ovos da experiência" ${ }^{37}$.

Em "Experiência e pobreza", dois aspectos são apresentados como centrais para a queda do valor da experiência: a barbárie e o acúmulo. Enquanto a primeira seria a responsável pelo empobrecimento da transmissão por causa do impossível do relato do terror das trincheiras, o segundo consistiria no excesso que preenche o salão burguês, cujo “'interior’ obriga o habitante a adquirir o máximo possível de hábitos, que se ajustam melhor a esse interior a que ele próprio" 38 . Nesse mundo desencantado,

32 BENJAMIN, Walter. Reflexões sobre a criança, o brinquedo e a educação, 2002, p. 21.

33 Ibidem, p. 22.

34 Ibidem, p. 24.

35 Idem, Obras escolbidas: Magia e técnica, arte e politica, 1985, p. 198.

36 Ibidem, p. 204.

37 Ibidem, p. 204.

38 Idem. "Experiência e pobreza", p. 118. 
nos termos de Weber, a felicidade só pode residir numa noção de milagre laica e capitalizada, que passa por um "ponto de fuga": "numa interminável perspectiva de meio, surge uma existência que se basta a si mesma, em cada episódio, do modo mais simples e mais cômodo" 39 .

Tanto o horror excepcional da guerra como a banalidade do hábito, resultante do acúmulo de bens e certezas, impediriam a transmissão e que o olhar se desvie o suficiente para encontrar os restos, como o trapeiro. Seja o teor ensimesmado de quem é submetido por um profundo trauma, sejam as determinações de finalidade e pragmatismo, o resultado é uma existência esvaziada precisamente por causa do excesso de sentido que condena a felicidade ou a protocolos e modelos de fabricação em série, ou a quimeras inatingíveis sempre em outros tempos e outros lugares.

Volto à prosa de Ginzburg e ao último dos fins de seus romances, mediada por dois comentários de Calvino sobre a autora. O primeiro deles destaca uma relação direta com o mundo, "nunca psicologizado, nunca intelectualizado, nunca lírica"40; e o segundo define o ritmo das narrativas como "uma cadência de repetição e tédio" tentativa é amarrar estas linhas com a seguinte proposta: se, por um lado, os quarenta anos que separam a cidade da casa - o primeiro do último romance - poderiam ser lidos com a experiência empobrecida de Benjamin, segundo a acepção da impossibilidade de transmissão, ainda restaria a possibilidade de experiência em lampejos de alegrias ásperas, amargas e cinzentas, que podem vir a ter lugar por causa do trabalho da memória.

O primeiro caminho está estritamente ancorado na forma: no primeiro romance, há uma narradora, um enredo e um movimento ascendente em direção à cidade - a protagonista atinge o objetivo de ter uma casa -, enquanto no último não se tem narração nem um enredo robusto, e o movimento é o de uma errância contínua: não se chega a lugar nenhum. Particularmente em relação à narração, Caro Michele poderia talvez ser lido como uma transição já que ainda nele há a presença intermitente de um narrador, e, em La città e la casa, não há mais onisciência nem perspectiva em primeira pessoa para conduzir uma história: restam apenas palavras soltas de múltiplos remetentes.

Em La città e la casa, as cartas comunicam muito pouco. As correspondências parecem ser os resíduos da transmissão que o século XX destruiu gradualmente: escrevem-se cartas como um recurso mínimo para fugir do silêncio da ausência e

\footnotetext{
39 Ibidem, p. 119.

40 "mai psicologizzato, mai intellettualizzato, mai liricizzato" (CALVINO, Italo. "Natalia Ginzburg o le possibilità del romanzo borghese", 2015, p. 5).

41 "una cadenza di ripetizione e di tedio" (Ibidem, p. 6).
} 
da experiência empobrecida. Em alguns momentos, elas são usadas para relatos de acontecimentos trágicos, mas, nesses casos, são feitas referências a ligações prévias que já tinham dado conta dos anúncios desses eventos tristes. A correspondência, aliás, parece ter uma função oposta à da informação, porque ela comporta coisas que a comunicação imediata dos telefonemas não consegue carregar. Com o humor e a simplicidade que são característicos da autora, uma frase soa bastante provocadora nesse sentido: "Nas ligações internacionais, se pensa muito no dinheiro que vai embora. Assim acaba que não se diz nada. Numa carta, dá para dizer muito mais." ${ }^{42}$. Isso que se diz mais nas cartas é lido por Clementelli como recurso para as vidas presas em uma profunda solidão:

\begin{abstract}
O monólogo, mesmo quando é diálogo, parece, portanto, a única via de salvação para fazer frente a invasões, ambiguidades, perplexidades autocentradas, desde que - para além das intenções programáticas - a única certeza não seja revelada: aquela relativa a uma absoluta e desesperada solidão ligada ao impossível da comunicação. E qual poderia ser a forma mais direta e imediata para o desenrolar de fluxos de consciências que não a escrita de si mesmo, como são as cartas e os diários, ou os dois juntos numa terceira e mais sutil forma? ${ }^{43}$.
\end{abstract}

A comunicação impossível borra os contornos de finalidade das cartas e as aproxima da escrita de um diário. Na crítica epistolar, também se encontram alguns comentários relativos a um processo anterior de elaboração, por parte do remetente, que antecede a participação do destinatário. Brigitte Diaz nomeia esse primeiro momento de "formulação escritural de si" que "tem primazia sobre o simples desejo de comunicação" ${ }^{44}$. E se não é comunicação que está em questão, ainda há uma expectativa de retorno, ou, uma forma de expressão que solicita a confirmação do vínculo de afeição ${ }^{45}$ como uma brecha da solidão e do silêncio.

Diferente do primeiro romance, quando "os mortos metem medo", em La città e la casa, as mortes - junto aos deslocamentos geográficos - são os únicos eventos

42 "Ma nelle telefonate internazionali, uno pensa ai soldi che se ne vanno via. E cosí si finisce col dire niente. In una lettera si dicono tante più cose” (GINZBURG, Natalia. La città e la casa, 1997, p. 119). 43 "Il monologo, anche quando è dialogo, sembra dunque l'unica via di salvezza per sbaragliare invasioni, ambiguità, smarrimenti egotistici, a meno che - al di là delle intenzioni programmatiche - non sveli la sola certeza: quella di una assoluta, disperata solitudine, di una comunicazione impossibile. E quale la forma espressiva piú direta, imediatta di questa corrente di conspevolezza, se non la scrivere a se stessi, lettera o diario, o tutt'e due o una terza, piú sottile variante?” (CLEMENTELLI, Elena. Invito alla lettura di Natalia Ginzburg, 1986, p. 95).

44 DIAZ, Brigitte. O gênero epistolar ou o pensamento nômade. 2016, p. 199.

45 HAROCHE-BOUZINAC, Geniviève, Escritas epistolares, 2016. 
que afetam o ritmo da narrativa e que poderiam dar o tom de enredo para esse texto de cadência lenta ao ponto de se aproximar do tédio, para usar a palavra de Calvino. Não é que os mortos não metam mais medo, é que o contexto não permite que o olhar seja desviado deles. No romance, seria possível sistematizar as posições em relação às perdas de duas maneiras: os que padecem das lembranças em excesso e os que conseguem desfrutar de um lampejo da alegria amarga, áspera e cinzenta.

A suposição da primeira posição parte de fragmentos como o de uma adolescente, que prefere dividir o quarto com um irmão mais novo a herdar o quarto vazio de outro irmão que morrera com dois dias de vida porque "diz que não consegue esquecer. Se dormisse naquele quarto, não faria outra coisa além de sonhar com crianças mortas" 46 . Ou de um jovem que perde a amiga que morava com ele e a filha dela, que ele adotara formalmente, e escreve ao pai relatando que o lugar onde reside "se tornou odioso em cada canto, em cada pedaço de parede" ${ }^{47}$. Ou ainda de um homem que perde um amigo que morava no apartamento debaixo do seu e escreve a uma amiga para dizer sobre os efeitos do imóvel desocupado: "A ideia de ter aquele apartamento vazio embaixo de mim me dá uma grande tristeza. Queria ir embora desta casa. Aqui tenho lembranças demais" ${ }^{48}$. Marcas intangíveis de ausentes são espacializadas de tal forma que as paredes repelem: lembrar é um peso e ressalta o espaço vago deixado por quem não mais está.

Já a segunda posição é delineada a partir das cartas trocadas pelos dois personagens que têm maior centralidade no romance: Giuseppe e Lucrezia. O primeiro é o autor da carta que abre o livro, e a segunda, da que fecha. Giuseppe deixa a Itália para viver nos Estados Unidos porque se sente carente de proteção e o irmão, com ternura autoritária, é sua referência protetiva. Pouco depois de chegar ao país estrangeiro, o irmão de Giuseppe morre subitamente. Contrariando os pedidos e as expectativas dos familiares e amigos, o personagem decide ficar nos Estados Unidos e seguir dividindo uma casa com a viúva do irmão: "Ela era cara ao meu irmão e por isso é a única coisa que me resta dele" ${ }^{49}$. Ainda que se sinta um hóspede na casa, é melhor ficar e ter esse resíduo do irmão perdido do que voltar para o lugar natal.

São muitas as perdas que marcam as vidas de Lucrezia e Giuseppe depois do último encontro dos dois, relatado na segunda carta do romance. Giuseppe

\footnotetext{
46 "dice che non lo può dimenticare. Se dormisse in quella stanza, non farebbe che sognare com bambini morti” (GINZBURG, Natalia. La città e la casa, 1997, p. 163).

47 "è diventato odioso in ogni angolo, in ogni pezzo di muro"(Ibidem, p. 195).

48 "L'idea di avere sotto di me quell'appartamento vuoto mi dà una grande tristeza. Vorrei andarmene da questa casa. Qui ho troppi ricordi" (Ibidem, p. 230).

49 "Era cara a mio fratello e cosí è la sola cosa che mi resta di lui” (Ibidem, p. 83).
} 
ainda perde a esposa e seu filho Alberico é assassinado na Itália. A morte do filho de Giuseppe é um golpe duro também para Lucrezia porque, depois de ser abandonada pelo amante e perder um filho bebê, ela desenvolve uma profunda e levemente insólita amizade com Alberico. Lucrezia havia sido, anos antes, amante de Giuseppe e conhecia Alberico desde a infância, mas depois de cada um perder um filho, acontece uma aproximação que parece ser um resquício de vida para duas existências profundamente machucadas. É este o conteúdo da carta de desfecho do romance: Lucrezia conta ao seu amigo o impacto da perda de Alberico e recorda um breve momento alegre que viveu com o jovem. A missiva destinada a Giuseppe é uma das poucas sem qualquer tipo de saudação, ela começa listando as coisas pelas quais a personagem lamenta:

\footnotetext{
Sinto muito que sua mulher esteja morta.

Sinto muitíssimo que não nós vimos quando vocês esteve em Roma (...) Quando voltei a Roma, Piero me contou.

Fico contente por ter ido a Monte Fermo com ele aquela vez com o Prisma azul. Fico contente por termos vistos juntos o hotel Panorama.

Alberico não estava alegre naquele dia, mas ria frequentemente. Eu ria com ele. Era belíssimo rir junto com ele. (...)

Éramos amigos, aquele tipo de amizade que é de um modo e não muda nunca: permanece segura e inalterada para sempre.

Você diz que deseja imensamente me rever e, ao mesmo tempo, que não deseja de fato. Entendo você. É a mesma coisa para mim (...)

É verdade que aconteceu muita coisa a você e a mim nos últimos anos. Aconteceram muitas coisas. Por isso, se nos revíssemos, não conseguiríamos falar nada por um tempo.

Também usei o futuro do pretérito, sabe-se lá o porquê. Por essa razão, não devemos nos ver nunca mais, seja nesta vida, seja numa próxima.

Não é verdade que eu não sei mais como você é. Sei muitíssimo bem. Lembro-me de você como se o tivesse diante dos olhos.
}

Os seus cabelos longos e ralos. Os seus óculos. O seu nariz longo. As suas pernas longas e magras. As suas mãos grandes. Elas eram sempre frias, mesmo quando fazia calor. Lembro-me de você assim ${ }^{50}$.

50 "Mi dispiace che tua moglie sia morta. Mi dispiace moltissimo che non siamo visti quando sei venuto a Roma (...). Quando sono tornata a Roma, Piero me l'ha detto. Sono contenta di essere andata a Monte Fermo, quella volta, sulla Prisma azzura. Sono contenta che abbiamo guardato l'albergo Panorama. Non era allegro, Alberico, ma rideva spesso. Ridevo con lui. Era belissimo ridere insieme (...)Dici che desideri immensamente di rivedermi, e nello stesso tempo non lo desideri affato. Ti capisco. É la stessa cosa per me (...) É vero che a te e a me, in questi anni, sono succese troppe cose. Per questo, se dovessimo rivederci, per un poco non riusciremmo a parlare. Ho adoperato anch'io il condizionale, chissà perché. Per quale ragione mai dovremmo rivederci, in questa vita o nell'altra. Non è vero che non so piú como sei. Sei benissimo come sei. Ti ricordo come se ti avessi davanti. I tuoi pochi e lunghi capelli. I tuoi occhiali. Il tuo lungo naso. Le tue gambe lunghe e magre. Le tue mani grandi. Erano sempre fredde, anche quando faceva caldo. Cosí ti ricordo" (Ibidem, p. 234). 
Lucrezia registra dois compromissos com lembranças de ausentes: Alberico e Giuseppe, pai e filho, o primeiro morto e o segundo distante. A imagem que guarda de Alberico é caracterizada pela lembrança bonita de rir junto com o amigo. Na carta que relata essa viagem, no entanto, Lucrezia narrara a dor que encontrou no local desse Hotel Panorama, por ser a estrutura da casa em que habitara por muitos anos. O dia foi vivido com pesar, mas ele deixou um resíduo singelo de uma risada conjunta que pode ser um alento, uma vez que quem riu com ela foi brutalmente subtraído de sua vida.

Quando fala de mágoas que pairam entre os dois, o encontro ainda é uma possibilidade. Por fim, ela se afasta do condicional e retira a dúvida de um reencontro ao descartar a possibilidade dos dois se virem novamente. A lembrança emerge a partir da definição da impossibilidade de estarem juntos. O ponto final da carta encerra a possibilidade dos dois se encontrarem ao passo que traz o ausente para mais perto ao evocá-lo por meio das palavras. Lucrezia recorda a imagem do amigo para transformála em frases encadeadas e levar o ausente para "diante dos olhos". "Mudanças, trocas de apartamento, coabitações forçadas ou voluntárias se dão em uma dimensão fragmentária e parcial, na qual os indivíduos se aproximam e se perdem, como o 'reflexo de um espelho partido" "51, comenta ainda Clementelli sobre o romance. É mesmo um espelho partido que compõe a imagem de Giuseppe, nas palavras de Lucrezia que, como Osvaldo de Caro Michele, parece se confortar com nada para atenuar um nada que também contamina seu olhar para com a vida.

O ritmo da carta é fragmentário e contraditório: a realidade nua que Magrini, Arêas e Calvino destacam na prosa de Ginzburg parece residir precisamente na crueza de representação das incoerências humanas. As palavras rareiam: há pouco a dizer e quase nada a comunicar depois de tantas perdas. Os parágrafos são curtos, há pouquíssimas conjunções: o ritmo truncado parece dizer sobre a experiência empobrecida na medida em que as palavras não dão conta do desolamento. $\mathrm{O}$ desolamento, contudo, não é completo, há resíduos de lembranças que são, ao menos, "gélidos consolos". Delia não pode lembrar, e, então, não há consolo. Lucrezia e Osvaldo podem. A alegria como proposição ética tem uma direção contrária ao empobrecimento da experiência, ela é a afirmação de uma ínfima margem ainda viável perante a força irrefreável desse movimento.

Os quarenta anos que separam os fins do primeiro e do último romance parecem deslocar possíveis estatutos da memória, da lembrança tolhida às palavras

51 "Traslochi, scambi di appartamento, coabitazioni forzate o volontarie avvengono in uma dimensione frammentaria e parziale, nella quale gli individui si avvicinano e si perdono, "schegge d'uno specchio rotto."

CLEMENTELLI, Elena. Inivitto alla lettura di Natalia Ginzburg. 1986, p. 96. 
que guardam presenças de ausentes. Retomando Espinosa, a saudade pode ser uma falta que coloca o desejo em movimento ou uma falta que ressalta a perda e imobiliza. A imagem formada pelo espelho partido, em La città e la casa, parece carregar as duas direções da saudade. Ainda que haja um tom melancólico, a escrita de uma carta é uma forma de tomada de posição perante a perda, e a conjugação do recordar no presente não é, ao menos, a imobilidade completa: existem os gestos de registro e o endereçamento da falta.

\section{A memória acesa e os lampejos alegres}

Ginzburg, com sua poética do resíduo, salva o instante e permite pontualmente que duas solidões se encontrem: remetente e destinatário têm um ao outro, ainda que mediados pela distância e pelo silêncio. A experiência poderia sobreviver, então, porque a carta não se submete à informação e à comunicação pragmática. Intervalada pelo hiato de tempo e espaço que separa leitor e redator, as missivas convocam quem entrega e quem recebe as palavras, de tal forma que a sensação esmagadora de solidão pode arrefecer, nem que no limitado tempo da leitura e da escrita. Fica a proposta de que a experiência sobrevive nisso que está entre as frases curtas que fazem os contornos de Giuseppe caberem no "lembro-me de você assim". Como nos versos de João Cabral da epígrafe, não se trata de nitidez, mas da atmosfera que toma lugar na falta de exatidão.

Os versos de "Desejo de Regresso", de Cecília Meireles, podem ajudar a arrematar a discussão em torno da alegria como experiência possível num mundo empobrecido de palavras não domesticadas pelo sentido: "Porque há doçura e beleza/ na amargura atravessada/ quero a memória acesa/ depois da angústia apagada" ${ }^{" 52}$. A amargura, para a poeta brasileira, carrega doçura e beleza e a memória pode ser sucessora da angústia. A amargura, em Ginzburg, é adjetivo para qualificar a alegria. E, no filme de Fellini, a amargura das perseguições políticas e das perdas aparece encadeada em meio a fragmentos de risos e pequenas euforias. Outro ponto em comum poderia ser encontrado com a leitura de que a lembrança é apresentada de forma ambivalente, como o que comporta claridade e escuridão sem escansão precisa: um movimento singelo e quase mínimo, mas que não é o recuo diante do medo que os mortos despertam. Alegria, então, como uma afirmação da vida, convite ao enterro dos mortos, uma postura perante a saudade que passa pelo desejo que pode brotar $\mathrm{da}$ falta.

52 MEIRELES, Cecília. Antologia poética, 2013, p. 72. 


\section{Referências Bibliográficas}

ARÊAS, Vilma. "Ofício de escrever". In: GINZBURG, Natalia. Caro Michele. São Paulo: Cosac Naify, 2009, p. $159-175$.

BARTHES, Roland. Journal de denil. Paris: Éditions du Seuil, 2009

BENJAMIN, Walter. Obras escolbidas III: Charles Baudelaire: um lírico no auge do capitalismo. São Paulo: Editora Brasiliense, 2000.

BENJAMIN, Walter. Obras escolbidas: Magia e técnica, arte e politica. São Paulo: Editora Brasiliense, 1985

BENJAMIN, Walter. Reflexões sobre a criança, o brinquedo e a educação. São Paulo: Editora 34, 2002.

CALVINO, Italo. "Natalia Ginzburg o le possilità del romanzo borghese". In: GINZBURG, Natalia. La voci della sera. Torino: Einaudi, 2015, p. 3 - 11.

CLEMENTELLI, Elena. Invito alla lettura di Natalia Gin₹burg. Milano: Mursia editore, 1986.

DIAZ, Brigitte. O gênero epistolar ou o pensamento nômade. São Paulo: Edusp, 2016.

ESPINOSA. Ética. São Paulo: Edusp, 2015.

AMARCORD. Direção: Federico Fellini. Itália: Vides Cinematografica, 1973. (124 min), 1 DVD, color.

GAGNEBIN, Jeanne. Lembrar escrever esquecer. São Paulo: Editora 34, 2006.

GARBOLI, Cesare. "Opere di Natalia Ginzburg”. In: GINZBURG, Natalian. As pequenas virtudes. São Paulo: Cosac Naify, 2015. p. 141 - 147.

GINZBURG, Natalia. "Un matrimonio in provincia”. In: Fições n. 11. Rio de Janeiro: 7 Letras, 2003.

GINZBURG, Natalia. As pequenas virtudes. Tradução de Maurício Santana Dias. São Paulo: Cosac Naify, 2015.

GINZBURG, Natalia. Caro Michele. Torino: Giulio Einaudi editore, 2001.

GINZBURG, Natalia. Caro Michele. Tradução de Homero Freitas de Andrade. São Paulo: Cosac Naify, 2009.

GINZBURG, Natalia. La città e la casa. Torino: Giulio Einaudi editore, 1997.

GINZBURG, Natalia. Opere, volume primo. Milano: Arnoldo Mondadori Editore, 1986.

GINZBURG, Natalia. Todos os nossos ontens. Tradução de Maria Betânia Amoroso. São Paulo: Companhia das Letras, 2020.

HAROCHE-BOUZINAC, Geneviève. Escritas epistolares. São Paulo: Edusp, 2016 
MAGRINI, Giacomo. "Introduzione". In: GINZBURG, Natalia. Tutti i nosti ieri. Torino: Giulio Einaudi editore, 1996. p. 5 - 12.

MEIRELES, Cecília. Antologia poética. São Paulo: Global editora, 2013.

MELO NETO, João Cabral de. Museu de tudo. Rio de Janeiro: Alfaguara, 2009.

SHAKESPEARE, William. A tragédia de Macbeth. Tradução de Rafael Raffaeli. Florianópolis: Editora da UFSC, 2016.

Submissão: 06/05/2020

Aceite: 06/08/2020

https://doi.org/10.5007/2176-8552.2019.e73603

Esta obra foi licenciada com uma Licença Creative Commons Atribuição-NãoComercial 4.0 Internacional. 